\title{
Percepções do médico-chefe a respeito de atividades educativas em Postos de Assistência Médica.
}

\section{Perceptions of head doctors regarding the educational activities undertaken in Municipal Health Services}

\author{
Isabel Maria Teixeira Bicudo Pereira *, Márcia Faria Westphal *, Glacilda Telles Menezes Stewien *
}

\begin{abstract}
PEREIRA, I.M.T.B. et al. Percepções do médico chefe a respeito de atividades educativas em Postos de Assistência Médica. Rev. Saúde públ., S. Paulo, 25: 306-14, 1991. Realizou-se pesquisa com médicos-chefe dos Postos de Assistência Médica (PAMs) da Prefeitura Municipal de São Paulo, Brasil, com o objetivo de investigar seus conhecimentos, expectativas e predisposiçōes em participar e incentivar as programações educativas nos PAMs. Utilizou-se questionário, com questões abertas e fechadas que foi respondido por $\mathbf{8 8 , 6 \%}$ dos médicos-chefe dos PAMs. Os resultados demonstraram que o conceito de saúde da maioria dos médicos-chefe dos PAMS $(66,3 \%)$ coincide com o emitido pela Organização Mundial da Saúde. Apenas 2,9\% consideram que saúde está relacionada a qualidade de vida. Educação em saúde foi considerada por 70,0\% como transmissão de informação; somente $6,7 \%$ reconheceram sua responsabilidade no processo de transformação social e de saúde. $\mathrm{Na}$ visão de $68,2 \%$ as ações educativas são reconhecidas como úteis para conscientizar o usuário sobre a importância do tratamento de doenças. Essas ações, seu planejamento, execução e avaliação são reconhecidas como responsabilidade de todos que trabalham nos PAMs mas, especialmente, das enfermeiras, assistentes sociais e educadores de saúde pública. Dificuldades foram mencionadas na execução de atividades educativas, referentes à falta de material suficiente e local adequado para sua realização, falta do educador de saúde pública e, principalmente, falta de motivação de funcionários e da própria população. A maioria dos médicos-chefe reconhece a importância das ações educativas, reconhece que são desenvolvidas por pelo menos parte de sua equipe embora, muitas vezes, precariamente, com dificuldades técnicas e administrativas.
\end{abstract}

Descritores: Médicos. Conhecimentos, atitudes e prática. Educação em saúde.

\section{Introdução}

Dados os compromissos políticos ocorridos recentemente, no país, de resgate da dívida social, foi assinado, no dia 20 de julho de 1987 , decreto que criou o Sistema Unificado e Descentralizado de Saúde-SUDS ${ }^{7}$, visando a consolidar ou permitir o desenvolvimento qualitativo das experiências de integração de serviços e racionalização de recursos de acordo com o ideário da Reforma Sanitária ${ }^{6}$.

Nesta nova forma de organização são criados mecanismos de concretização dos princípios estabelecidos para reger o nosso Sistema Nacional de Saúde: integração das açð̃es para superar a dicotomia preventiva-curativa; descentralização na

\footnotetext{
* Departamento de Prática de Saúde Pública da Faculdade de Saúde Pública da Universidade São Paulo. São Paulo, SP - Brasil.
}

Separatas/Reprints:I.M.T.B. Pereira - Av. Dr. Amaldo, 715 01255 - São Paulo, SP - Brasil.

Publicação financiada pela FAPESP. Processo 90/4602-1. gestão de ações e serviços, permitindo uma adaptação contínua à realidade em transformação; regionalização e hierarquização de ações e serviços para permitir o atendimento das necessidades de diferente complexidade em diferentes níveis com referência e contra-referência; fortalecimento do papel do município; atendimento de acordo com as necessidades da população; qualidade do atendimento compativel com o estágio de desenvolvimento do conhecimento e com os recursos disponiveis, formação de profissionais de saúde integrada ao sistema. Destes principios e sua operacionalização consideramos importante comentar dois deles, a integração e descentralização que fornecem elementos para definição de nosso problema de estudo.

A necessidade de integração de serviço era há muito tempo sentida em função da multiplicidade de instituiçðes envolvidas no mesmo tipo de açõcs: Ministério da Saúde, Previdência Social, Secretarias Estaduais e Municipais de Saúde, além de instituições privadas que operacionalizam essa integração. 
Um dos intuitos das autoridades governamentais ao descentralizar a gestão desses serviços integrados foi deixar a gerência mais perto da ação. $\mathrm{O}$ poder central já há muito vinha sentindo dificuldades no desenvolvimento de ações de planejamento, organização, controle e direção que respondessem às necessidades da população, ao contrário do poder local que convive diariamente com os moradores de suas cidades e conhece mais suas necessidades. A expectativa era de que, se o serviço não desenvolvesse suas atividades a contento, que a população denunciasse concretizando o que se denominou "controle social dos serviços de saúde".

A implantação da descentralização vem ocorrendo de acordo com a política de cada Estado. No caso de São Paulo, a opção foi pela municipalização onde a assinatura do convênio SUDS determinou a passagem de recursos humanos e materiais de origem federal para o gerenciamento do Estado, caminhando-se assim para a concretização do conceito de "comando único". O Estado, por sua vez, repassou às Prefeituras, que com ele fizeram convênio, recursos financeiros, materiais e humanos visando ao desenvolvimento das atividades de saúde de caráter preferencialmente primário, mas podendo também aprofundar esse nivel de atendimento.

$\mathrm{Na}$ realidade, em São Paulo a municipalização vem ocorrendo gradativamente no interior do Estado não tendo ainda se concretizado no Município de São Paulo. Pensa-se que para tal estrutura funcionar, onde já ocorreu a municipalização e no Município de São Paulo onde está para ocorrer, algumas mudanças mais profundas, especialmente em nivel dos funcionários, devem acontecer. Os princípios básicos da Reforma Sanitária precisam ser incorporados, para que se desenvolva um processo amadurecido entre serviços de saúde e população.

Para isso é necessário, entre outras coisas, que se desenvolvam projetos de educação continuada, que permitam aos trabalhadores de saúde "buscar informaçōes científicas e tecnológicas necessárias à interpretação de situaç̃̃es vigentes na sociedade, tornando transparentes seus objetivos e seus comprometimentos ideológicos"; "comprometer-se com a causa popular", "compreender o processo ensino-aprendizagem que ocorre entre as pessoas, grupos e classes sociais"12.

Sendo os médicos-chefe das Unidades Básicas de Saúde (UBS) locais, os representantes oficiais do sistema municipal de saúde junto à população $\mathrm{e}$ os responsáveis pela implantação de um novo sistema com novas idéias, e considerando que cabe às Unidades sob sua responsabilidade não só oferecer atendimento médico, mas o preparo dos atendidos, ou melhor, da coletividade, na luta pelo seu direito à saúde, a partir do entendimento das con- dições de vida que interferem no processo saúdedoença, resolvemos realizar o presente estudo. A finalidade é questionar a forma como os médicoschefe percebem o trabalho de saúde com a população e a educação em saúde, atualmente considerada instrumento acionador da participação do pessoal de saúde na gestão dos serviços e da população no equacionamento e soluçãa dos problemas de saúde da coletividade. Os dados obtidos poderão subsidiar o poder municipal no reconhecimento dos problemas e necessidades do nível local e contribuir para a solução dos mesmos, especialmente no que se refere ao preparo do pessoal que estará liderando a implantação do novo sistema: os chefes de Postos de Assistência Médica (PAMs).

\section{Metodologla}

A população de estudo foi constituída pelos médicos-chefe de todos os PAMs da Secretaria de Higiene e Saúde da Prefeitura Municipal de São Paulo (PMSP), que em 1989 perfaziam um total de 115 Unidades*.

$O$ instrumento de pesquisa foi um questionário semi-estruturado, que pressupunha autopreenchimento, composto por 24 questōes, das quais algumas fechadas, complementadas por questões abertas, e outras somente abertas. A introdução de questōes abertas segue a recomendação de Windsor e col. ${ }^{14}$, que reafirmam serem as mesmas imprescindíveis para se penetrar mais profundamente na essência e subjetividade do objeto de estudo.

A população foi caracterizada pelas seguintes variáveis: sexo, idade, tempo de serviço na prefeitura, ter feito Curso de Saúde Pública, e/ou curso de chefia, ser ou ter sido médico consultante.

Os conceitos de saúde e educação em saúde foram obtidos através de questôes abertas. Categorias de respostas, ou melhor, eixos temáticos de conceitos emitidos pelos respondentes foram categorizados pelas técnicas de análise de conteúdo ${ }^{2}$. Para tanto, reportou-se aos conceitos clássicos de saúde, encontrados na literatura ${ }^{1,4,10}$. Incluiu-se neste referencial teórico de análise o conceito difundido a partir da $8^{a}$ Conferência Nacional de Saúde ${ }^{6}$ e referendado na nova Constituição Federal do Brasil ${ }^{3}$.

Os parâmetros para análise do conceito de educação em saúde foram baseados na literatura $8,9,11,12$, onde se identificou um gradiente entre dois tipos

\footnotetext{
* Nessa época os PAMs pertenciam ao Departamento de Saúde da Comunidade e pretendiam atuar como "porta de entrada" da população no Sistema Municipal de Saúde. A partir de 1989 a Secretaria passa por mudanças em sua estrutura com o objetivo de preparar-se para a implantaçāo do Sistema Único de Saúde, na cidade de São Paulo.
} 
de visões. A mais tradicional, configura a educação em saúde como meio, complemento e suporte das açð̃es médico-sanitárias visando à sua maior eficiência, através da regulamentação e normatização de atividades, hábitos e comportamentos da população dentro dos padrões de normalidade sanitária ${ }^{11}$. A mais inovadora, e mais coerente com os ideais da Reforma Sanitária, define como finalidade da ação educativa o "desenvolvimento no indivíduo e no grupo da capacidade de anilisar criticamente a sua realidade, de decidir açōes conjuntas para resolver problemas e modificar situaçð̄es, de se organizar e realizar a ação e analisá-la com espírito crítico"8.

$\mathrm{O}$ valor e importância atribuídos à educação em saúde pelos médicos-chefe foram avaliados não só a partir de uma questão fechada e direta, que verificou a prioridade atribuída a esta última em relação a outras atividades desenvolvidas pela Unidade, mas principalmente através da justificativa solicitada para esta priorização.

A forma como a educação em saúde vem sendo desenvolvida foi identificada a partir de questōes sobre a inserção das açōes educativas assis. temáticas na prática diária do pessoal de saúde $\mathrm{e}$ atividades sistematizadas por processos clássicos de planejamento, supervisão e avaliação.

Como já foi dito, a interpretação das questões fechadas foi subsidiada pelas questóes abertas que qualificaram os eventos. Foi buscada a coerência e relação entre as respostas a diferentes questões, como sugerem Wetherell e Potter ${ }^{13}$ para análise do discurso, a partir de respostas a questionários.

Os questionários distribuídos tiveram alta percentagem de retomo $-(88,7 \%=102$ questionários $)$ ficando a diferença justificada por férias, licenças $e$ inexistência de chefia em alguns PAMs.

\section{Resultados}

\section{Características Gerais dos Médicos-Chefe dos PAMs da PMSP}

Os dados obtidos permitiram caracterizar a população de estudo como um grupo heterogêneo quanto à faixa etária, que varia de 25 a 60 anos, porém a maioria dela pode ser considerada jovem $(46,2 \% \mathrm{en}$ tre 25 e 35 anos e $72,1 \%$ entre 25 a 40 anos). Mais da metade $(56,2 \%)$ é do sexo feminino e a grande maioria $(80,8 \%)$ trabalha a menos de 10 anos na PMSP, Departamento de Saúde da Comunidade.

Apesar de prestarem serviço em Unidades de Saúde, que tem como objetivo a assistência à saúde da coletividade, somente $33,6 \%$ deles prepararam-se formalmente para lidar com as questões de saúde coletiva, especializando-se em saúde pública em diferentes instituições: UNAERP $(29,7 \%)$, USP $(27 \%)$, São Camilo $(24,0 \%)$ e FCMSC $(10,8 \%)$ *. A PMSP, entretanto, através da Secretaria de Higiene e Saúde, preocupa-se com o preparo das chefias para o exercício de sua função, pois a maioria dos médicos-chefe $(82,7 \%)$ foi indicada e frequientou o Curso de Chefia, promovido pela mesma.

Embora seja intenção das estruturas hierárquicas superiores que os médicos-chefe dos PAMs exerçam somente funções administrativas, entre elas o planejamento e supervisão de ações, grande parte deles $(58,7 \%)$ acumula à primeira a de Médico consultante. Os que não exercem função no momento $(38,3 \%)$ já exerceram no passado, mostrando que a maior parte já conhece, por experiências anteriores, os problemas práticos que o atendimento apresenta.

\section{Percepção dos médicos-chefe sobre o conceito de saúde e educação em saúde}

Na Tabela 1 estão sintetizadas as concepções de saúde emitidas pelos médicos-chefe. Mais da metade $(66,4 \%)$ fez sua a definição estabelecida na constituição da $\mathrm{OMS}^{10}$. Com pequenas diferenças, 22,3\% atribuiram o significado de "adaptação e equilíbrio" ao processo saúde-doença. Somente dois $(1,9 \%)$ definiram saúde conforme a $8^{\underline{a}}$ Conferência

Tabela 1. Conceito de saúde dos médicos-chefe dos Postos de Assistência Médica da Prefeitura Municipal de São Paulo, São Paulo, 1988.

\begin{tabular}{|c|c|c|}
\hline Conceito & $\mathrm{N}^{2}$ & $\%$ \\
\hline $\begin{array}{l}\text { É um estado de completo bem estar } \\
\text { físico, mental e social }\end{array}$ & 69 & 66,4 \\
\hline $\begin{array}{l}\text { É estado de constante adaptação para } \\
\text { manutenção do equilíbrio físico, mental e } \\
\text { social }\end{array}$ & 12 & 11,5 \\
\hline $\begin{array}{l}\text { É estado de equilibrio decorrente de } \\
\text { uma interaçāo harmônica do indivíduo } \\
\text { com o meio ambiente }\end{array}$ & 11 & 10,6 \\
\hline $\begin{array}{l}\text { É o bem estar do indivíduo, fisico e men- } \\
\text { tal decorrente da possibilidade de lazer, } \\
\text { trabalho, alimento e moradia }\end{array}$ & 7 & 6,7 \\
\hline $\begin{array}{l}\text { É um processo continuo e dinâmico, que } \\
\text { se envolve num momento histórico } \\
\text { afetando grupos sociais, com diferentes } \\
\text { qualidades de vida }\end{array}$ & 2 & 1,9 \\
\hline Nāo responderam & 3 & 2,9 \\
\hline Total & 104 & 100,00 \\
\hline
\end{tabular}

* UNAERP - Universidade de Ribeirão Preto; USP Universidade de São Paulo; São Camilo - Faculdade de Ciências de Saúde São Camilo; FCMS - Faculdade de Ciências Médicas da Santa Casa de São Paulo. 
Tabela 2. Conceito de educação em saúde dos médicoschefe dos Postos de Assistência Médica da Prefeitura Municipal de São Paulo. São Paulo, 1988.

\begin{tabular}{llll}
\hline Conceitos & $N^{\circ}$ & $\%$ \\
\hline
\end{tabular}

Processo de:

Transmissão de informações $\theta$ conhecimentos visando à adoção e mudança de comportamentos condizentes com a saúde

Assimilação de padrōes sociais e culturais, conhecimentos e normas, visando a mudança de comportamento necessária para a manutenção e promoção de saúde e prevenção de doenças

Desenvolvimento de aptidões do indivíduo e/ou comunidade, esclarecendo dúvidas, buscando soluçōes, objetivando a melhoria de saúde do indivíduo e da comunidade

Transformação que se estabelece entre a população e os profissionais de saúde, numa relação de ensino - aprendizagem de troca de conhecimentos científicos e populares

Não se aplica

Não responderam

Total

$104 \quad 100,00$

Nacional de Saúde realizada, em $1986^{6}$, como resultante da qualidade de vida dos diferentes grupos da sociedade.

$\mathrm{Na}$ Tabela 2 estão sumarizadas as percepções sobre educação em saúde dos médicos-chefe. $O$ que pode ser visto é que a maior parte $(43,2 \%)$ entende "Educação em Saúde" como "transmissão de informações" que deverá se traduzir em comportamentos definidos "a priori" como adequados à saúde.

Somente uma pequena parcela dos médicoschefe $(12,5 \%)$ aproximou-se da vertente inovadora da educação $0^{8,9,11,12}$, definindo-a como um trabalho crítico, de integração, de troca, um instrumento de transformação social, que permitirá a conscientização da população a respeito do processo saúde-doença e sua organização para a conquista de melhores condições de saúde ${ }^{3}$. Neste grupo estão os que enfatizaram o desenvolvimento de aptidסes $(5,7 \%)$ e no outro os que enfatizaram o processo de troca e a finalidade transformadora conforme definido no parágrafo acima $(6,7 \%)$. Uma maior percentagem de médicoschefe mostra ter incorporado elementos de uma "nova" concepção de educação ${ }^{12}$, o que não ocorreu com incorporação de uma "nova" concepção de saúde ${ }^{6}$.

\section{Percepção dos médicos-chefe sobre as açōes educativas desenvolvidas nos PAMs da PMSP.}

A grande maioria dos médicos-chefe dos PMAs (92,3\%) afirma que nas Unidades são desenvolvidas ações educativas. Quando questionados sobre a importância que essas ações têm em termos de prioridade, descobre-se que $68,2 \%$ as consideram muito importantes e prioritárias, enquanto $22,1 \%$ as julgam importantes, mas não prioritárias.

Para ilustrar o que caracteriza a opinião dos chefes quanto à prioridade ou não dessas ações, relacionamos a seguir alguns depoimentos.

As Açōes Educativas são prioritárias porque:

- "só o médico não resolve a questão da saúde";

- "educar é fundamental na prevenção, diagnóstico e tratamento precoce";

- "é preciso esclarecer a população que é ignorante";

- "cria nas pessoas uma consciência crítica da causa de seus problemas".

As Ações Educativas não são prioritárias porque: - "mais importantes que essas ações são as referentes a tratamento e vacinação",

- "elas não existem, como processo contínuo",

-"médicos e dentistas têm que atender a uma outra prioridade: são as consultas agendadas, (além das emergências do dia)", cujo número é pré-estabelecido pela Administração Central;

- "a população é displicente";

- "alta demanda e falta de espaço físico prejudicam ou impedem a sua realização".

\section{Açōes educativas informais}

Segundo os médicos-chefe, ações educativas informais são executadas, multiprofissionalmente, por todo o pessoal da unidade (técnico, auxiliar e ou administrativo), sendo que o pessoal de nível universitário participa com muito mais ênfase nessas atividades. Entre esses, os mais citados, em ordem decrescente, foram: médicos, enfermeiras, assistentes sociais, educadores. Dentistas e psicólogos aparecem em último lugar com percentagens iguais (Tabela 3).

A participação do pessoal auxiliar de enfermagem e/ou administrativo, nesse processo, ainda não é reconhecida pela maioria dos chefes, embora os dados coletados demonstrem que, de certa forma (Tabela 3), alguns já os percebem como educadores.

Cerca de $2 / 3$ dos chefes afirmam que, na realidade, todos os profissionais educam. 
Tabela 3. Percepção dos médicos-chefe dos Postos de Assistência Médica da Prefeitura Municipal de Săo Paulo, sobre os profissionais responsáveis pela realizaçăo de ações educativas*. Săo Paulo, 1988.

\begin{tabular}{lrr}
\hline Profissionais Responsáveis & Ne & $\%$ \\
\hline Nivel Universitário & & \\
- Médico & 64 & 61,5 \\
-Enfermeira & 51 & 49,0 \\
-Assistente Social & 49 & 47,1 \\
-Educador Sanitário & 44 & 42,3 \\
-Dentista & 24 & 23,1 \\
-Psicólogo & 24 & 23,1 \\
- Nutricionista & 3 & 2,9 \\
-Qualquer profissional & 5 & 4,8 \\
Pessoal Auxiliar de Enfermagem & 17 & 16,3 \\
-Auxiliar de Enfermagem & 16 & 15,4 \\
-Atendente de Enfermagem & 2 & 1,9 \\
-Visitadores & 5 & 4,8 \\
-Outros & & \\
Pessoal Auxillar Administrativo & 19 & 18,3 \\
-Oficial de Administraçăo & 22 & 21,1 \\
- Todos & 15 & 14,4 \\
-Outros & & \\
\hline
\end{tabular}

- Respostas múltiplas

Ações educativas formais

Quem propöe o desenvolvimento de açöes educativas

A opinião sobre quem deve ter a iniciativa de propor o desenvolvimento das açðes educativas concentra-se nos profissionais universitários que trabalham nos PAMs, especialmente o médico, educador e assistente social (Tabela 4). Apenas um considera que elas devam ser propostas pelos níveis superiores e implantados por decisão das chefias dos PAMs. Alguns (16,3\%) acharam que pode ser de iniciativa de qualquer funcionário.

Tabela 4. Percepção dos médicos-chefe dos Postos de Assistência Médica da Prefeitura Municipal de São Paulo, sobre os profissionais que propōem o desenvolvimento de açöes educativas": São Paulo, 1988.

\begin{tabular}{lcr}
\hline Profissionais resp. & $n^{\mathrm{e}}$ & $\%$ \\
\hline Nivel Universitário & & \\
Médico & 28 & 26,9 \\
Educador & 21 & 20,2 \\
Assistente Social & 14 & 13,5 \\
Dentista & 7 & 6,7 \\
Psiólogo & 7 & 6,7 \\
Enfermeira & 7 & 6,7 \\
Outros (profissionais & & \\
envolvidos no atendimento) & 7 & 6,7 \\
Qualquer funcionário do PAMs & 17 & 16,3 \\
Nivel hierárquico superior & 1 & 1,0 \\
\hline
\end{tabular}

* Respostas múltiplas

\section{Quem participa}

Os profissionais dentista, psicólogo e médico são os que, na prática, têm mais dificuldade em participar de açōes educativas formais (aqui entendidas como atividades planejadas tais como grupos de discussão e/ou de informação) em conseqüência da sobrecarga de demanda já programada para consulta e da qual têm que dar conta, e da cobrança de produção. Grande parte $(15,3 \%)$ atribui à "equipe multiprofissional" a execução de atividades educativas formais. Educador, assistente social e enfermeira e "até" atendente e auxiliares de enfermagem são os elementos que mais freqüentemente compõem estas "equipes".

\section{Quem planeja}

De acordo com a concepção de saúde predominante no grupo de estudo, a maioria dos médicoschefe $(80,7 \%)$ considera que as atividades educativas formais dos PAMs são planejadas e que do planejamento só participa a equipe envolvida no problema ou em uma determinada área de atuação. $\mathrm{Na}$ maior parte das vezes as equipes, sem a participação dos usuários, buscam identificar as necessidades da população local e programam ações para atendê-las.

\section{Existência de avaliação}

Da mesma forma que o planejamento, a avaliação também é considerada como realizada nos PAMs por $69,2 \%$ dos chefes. Esta atividade tem sido responsabilidade da equipe que a planejou e a executou, segundo a opinião de $40,3 \%$ dos médicos-chefe; $6,7 \%$ deles consideram que esta responsabilidade é unicamente da chefia da unidade. $O$ restante divide a sua opinião entre as afirmações de que avaliar é responsabilidade do chefe mais equipe; do profissional encarregado daquela atividade; de profissionais como enfermeira, assistente social e educador. Apenas um declarou que esta atividade pode ser responsabilidade de auxiliares e atendentes de enfermagem.

As ações educativas são avaliadas através de reuniðes, em que se discutem os resultados obtidos $(33,6 \%)$. Consideram que os efeitos da ação desenvolvida são também verificados pelas percentagens de retornos a consultas agendadas ou outras atividades marcadas $(6,0 \%)$, seguimento das orientaçð̃es $(11,5 \%)$ e comparação dos resultados obtidos com os objetivos propostos $(6,7 \%)^{*}$.

\footnotetext{
* \% resultantes de respostas múltiplas.
} 


\section{Características das açöes}

educativas desenvolvidas em geral

Coerentemente com as concepções de saúde e de educação em saúde, a maioria dos chefes $(88,4 \%)$ definiu as ações educativas tanto formais como informais, como o ato de transmitir informações sobre pré-natal, hipertensão, aleitamento, vacinação, entre outros.

Apenas 5,7\% consideraram o ato de educar em saúde como algo contínuo, um processo, presente em todas as atividades, objetivando o desenvolvimento da crítica, iniciativa, criatividade e senso participativo em todos os níveis.

Mais da metade dos chefes $(59,6 \%)$ afirma que o desenvolvimento das ações educativas, planejadas ou não, é supervisionado pela equipe, pela chefia, ou pelos profíssionais responsáveis pela área.

\section{Papel do profissional educador de saúde nos PAMs}

Embora somente um médico-chefe tenha se posicionado de forma a reconhecer que a responsabilidade de educar é do educador, quando questionados diretamente sobre o papel desse profissional quase metade $(44,3 \%)$ deles reconheceu como função do mesmo "desenvolver ações educativas com funcionários e comunidade". Entretanto, outros, reconhecendo que cabe a todos desenvolver atividades educativas, vêem o papel do educador como de "coordenador das ações educativas desenvolvidas na unidade" $(27,8 \%)$, "elo de ligação entre o serviço de saúde e a população" $(20,1 \%)$, "o que promove a integração da equipe multiprofissional, visando ao planejamento de programas" (16,3\%), "o que assessora a equipe quanto aos aspectos educativos do trabalho" $(7,6 \%)$, "o que supervisiona esta ações" $(6,7 \%)$, ou "as avalia" $(3,8 \%)$.

\section{Dificuldades no desenvolvimento de ações educativas em geral}

Segundo os médicos-chefe, algumas dificuldades vêm obstaculizando a implementação de ações educativas em nível de PAM (Tabela 5).

A maioria das dificuldades se refere a problemas ligados a equipe que trabalha em seu próprio PAM, formação do pessoal, interesse e integração. Uma parcela de $14,4 \%$ desloca o problema para a população mostrando a dificuldade de alguns profissionais relacionarem-se com a mesma. Outros ainda são de opinião que os níveis central e regional do Departamento de Saúde da Comunidade não provém recursos humanos (educador de saúde pública) e materiais que viabilizem a execução dessas tarefas.
Tabela 5. Percepcão dos médicos-chefe dos Postos de Assistência Médica da Prefeitura Municipal de São Paulo sobre dificuldades para o desenvolvimento de açōes educativas, São Paulo, 1988.

\begin{tabular}{|c|c|c|}
\hline Tipo de Dificuldades * & $N^{2}$ & $\%$ \\
\hline $\begin{array}{l}\text { Problemas ligados à equipe } \\
\text { - Formação técnica do pessoal } \\
\text { - Falta de interesse nas programaçóes } \\
\text { - Falta de integração entre os profissionais }\end{array}$ & $\begin{array}{l}43 \\
24 \\
17\end{array}$ & $\begin{array}{l}41,3 \\
23,1 \\
16,3\end{array}$ \\
\hline $\begin{array}{l}\text { Problemas da população } \\
\text { - Desintereresse, desinformação e pouca } \\
\text { participação dos usuários }\end{array}$ & 15 & 14,4 \\
\hline $\begin{array}{l}\text { Falta de recursos da unidade } \\
\text { - Falta de área física e recursos materiais } \\
\text { - Falta do educador de saúde pública }\end{array}$ & $\begin{array}{l}40 \\
13\end{array}$ & $\begin{array}{l}38,5 \\
12,5\end{array}$ \\
\hline Outros & 10 & 9,6 \\
\hline
\end{tabular}

- Respostas múltiplas.

\section{O espaço de discussão no PAMs}

De acordo com informações dos médicos-chefe dos PAMs, 92,3\% têm incluído no seu agendamento reuniões de funcionários realizadas com seguinte periodicidade: mensais $(55,7 \%)$, bimestrais $(3,8 \%)$ e semanais $(2,8 \%)$.

A discussão conjunta dos problemas dos PAMs é o principal motivo de sua convocação $(82,6 \%)$. Dentro desse tema maior, são trazidos problemas relacionados ao funcionamento, deficiências do serviço, insatisfação salarial, problemas administrativos e outros. Uma segunda motivação para encontros são as reciclagens informais, leitura de documentos e criação de novas atividades $(28,8 \%)$. São ainda utilizadas para avaliação dos programas em andamento $(11,5 \%)$ e análise das ações educativas planejadas para atender necessidades da população $(3,8 \%)$.

\section{Sugestôes dos médicos-chefe parao incremento das atividades educativas a nivel local}

De acordo com as dificuldades apontadas pelos chefes dos PAMs para o desenvolvimento de atividades educativas, foram feitas sugestões de modificação, que foram sintetizadas por temas:

1. provimento de recursos materiais e humanos necessários ao desenvolvimento de atividades educativas;

2. preparo do pessoal sobre importância das açōes educativas, seus métodos e técnicas;

3. organização de atividades formais desde local, planejamento, esquema de supervisão e outros. 
A existência de sugestôes mostra que, apesar das dificuldades, existe interesse das chefias em que as açōes educativas ocorram e que se desenvolvam como outras atividades de assistência.

\section{Comentários}

O equacionamento da questão da saúde no nosso país está passando por um processo de revisão de suas bases conceituais e de sua prática.

A proposta do SUDS, que se baseia na concepção ampla de saúde e pressupõe a valorização do Município, como responsável pela integração política e financeira das instituiçōes que participarão do equacionamento dos problemas de saúde locais, aponta para alguns caminhos, entre eles formação da consciência coletiva do direito à saúde, impulsionadora de transformação das condições de vida e melhoria dos níveis de saúde.

Os dados do presente trabalho mostram que o futuro (o convênio de municipalização ainda não foi efetivado) representante oficial do novo sistema de saúde, os médicos-chefe dos PAMs da PMSP, estão distantes do novo ideário proposto tanto em termos de saúde, quanto de educação. A análise desta questão é de importância fundamental, especialmente porque acreditamos que a percepção das práticas educativas em saúde e 0 direcionamento dado às mesmas pelas chefias são reflexos das concepções dos médicos-chefe, mediadas pela realidade local. Identificando os conceitos de saúde e educação em saúde emitidos, verificamos que representam diferentes maneiras de compromisso consciente e inconsciente com diferentes concepções de saúde e/ou diferentes tendências educacionais.

A grande maioria adotou uma visão idealizada da saúde, que encontra muito dos seus fundamentos na moralidade social, que é a concepção de saúde de Organização Mundial da Saúde (OMS).

$O$ fato de a maioria estar assumindo esta concepção de saúde, indica em relação a concepção biologizante da saúde, uma mudança qualitativa, que tem tido reflexos positivos no exercício das práticas de saúde e educação. Essa mudança revelou-se no presente trabalho pcla demonstração, por $70 \%$ dos médicos-chefe, da compreensão do papel relevante da educação no processo de melhoria da saúde da população e da responsabilidade de todos e cada um dos que trabalha com a clientela no sucesso ou fracasso desse processo conforme já assegurava Cleary5. Foi ainda expressa pela adoção de um modelo de atendimento individual ou multiprofissional, que integra o componente educativo tanto nos consultórios como fora deles. $O$ questionamento que foi feito na apresentação de "dificuldades para realização de atividades educa- tivas, a exigência quantitativa de número de atendimento de consultas competindo com atividades grupais, multiprofissionais, parece também reflexo de um novo modo de pensar, que busca o tipo ideal de saúde, através de ações racionais e planejadas de transmissão de informação e de normas.

Outra concepção, que foi expressa por um número razoável de médicos-chefe, foi a dos que qualificaram saúde como adaptação e equilíbrio e que, provavelmente, consideram a causalidade da doença, função de vários fatores - agente, hospedeiro e ambiente - que se acham inter-relacionados e em constante equilíbrio. Ao utilizarem fatores externos naturais, como critério para analisar o equilíbrio/desequilíbrio na explicação de saúde, dão outro salto qualitativo, porém sem desvendar a determinação econômico-social da doença. Sendo o equilíbrio colocado como "disfunção de órgãos", geralmente é de se esperar que a educação $\mathrm{em}$ saúde seja concebida como uma intervenção, que deve prevenir ou corrigir comportamentos que provocam esta disfunção. Esta visão de saúde incorpora a educação como uma prática necessária para criar e mudar comportamentos e atitudes que interfiram no bom funcionamento do organismo e por extensão na saúde do grupo e da comunidade 9 . $\mathrm{Na}$ realidade, parte dos que mostraram assim pensar identificaram como função das açðes educativas diminuir ou eliminar a "ignorância", pois esta é importante fator desencadeador de doença. Outra parcela ainda $(31,7 \%)$ a considerou como um processo capaz de produzir nos indivíduos a assimilação de padrões ou normas e corrigir desvios das mesmas para evitar o "desequilíbrio" e a "doença". Geralmente os que pensam assim imaginam a, desordem, a desobediência às normas estabelecidas, também um fator de desequilíbrio que conduz à doença, e atribuem à educação o papel de controlar e de estabelecer normas.

Estas duas frações de médicos-chefe que se posicionaram a favor destas duas primeiras abordagens de educação, embora representem uma visão mais "moderna" de saúde, representam, também, uma visão da prática educativa mais próxima da vertente tradicional normatizadora e regulamentadora e que vem sendo assumida pelos serviços de saúde, isto é, "a diretriz que tem norteado a ação educativa está concentrada na dimensão comportamental, numa visão simplista de que conhecimentos e atitudes adequadas sobre saúde constituem fatores indicativos de condutas adequadas" 7 .

$\mathrm{Na}$ visão da maioria dos médicos-chefe a ação educativa é uma forma de influir sobre a população para que esta substitua suas práticas individuais de saúde, reforçando a idéia de que a culpa pela eventual perda da saúde é de responsabilidade da pessoa e nada tem a ver com suas condições de 
vida. Nesse sentido, assume a função de instrumento de reprodução da situação vigente no campo da saúde e de modo geral no país.

Em relação a "nova" concepção da saúde, defendida na $8^{\mathrm{a}}$ Conferência Nacional de Saúde, verificamos que a mesma não foi absorvida pelas chefias locais, apesar de tão discutida em nível de academia e dos níveis hierárquicos mais altos das instituições de saúde.

Tentando estabelecer uma relação entre a formação dos chefes em saúde pública e suas concepções de saúde/doença, observamos que mais da metade dos que fizeram Curso de Saúde Pública $(18,3 \%)$, o fizeram após a $8^{\mathrm{a}}$ Conferência Nacional de Saúde, entre os anos de 1986 e 1988. É de estranhar que somente 2 destes $(1,9 \%)$ tivessem introjetado uma nova visão de saúde.

O comprometimento com a "nova" concepção de saúde, veiculada a partir da $8^{\text {a }}$ Conferência Nacional de Saúde, significaria a incorporação dos determinantes econômico-sociais na explicação do processo saúde/doença e a adoção de uma visão participativa de educação, que incorpora o pessoal auxiliar de saúde e a população no processo decisório de planejamento e avaliação. Isto não está ocorrendo nos PAMs, uma vez que os médicoschefe nem mencionaram estes entre os que participaram de planejamento e avaliação.

Para que a educação em saúde pública possa contribuir para os objetivos da saúde no Município, Estado e/ou País, de democratização do acesso a serviços assistenciais de qualidade e a longo prazo em mudanças de estrutura e organização social geradoras de doença, de acordo com a nova visão de saúde e educação, precisa se transformar ideológica e tecnicamente. É necessário que se torne uma prática comprometida, um instrumento para preparar a população atendida para desvendar não só os determinantes individuais do processo saúde, mas também os econômico-sociais. Assim se desenvolvendo se transformará num elemento acionador da luta política da população pelo direito à saúde, colaborando para a transformação da realidade social. Ainda é necessário, a par de ser percebida na sua nova feição, que seja acionada como uma prática de metodologias específicas, que exigem um mínimo de preparo de quem oriente o processo e um máximo de recursos para sua efetivação. Esta visão parece estar sendo incorporada por uma minoria de médicos-chefe.

Nas sugestōes dos médicos-chefe o aspecto técnico é contemplado, lembrando a necessidade da presença de um especialista de educação em nível local e solicitando recursos auxiliares para o desenvolvimento das ações educativas. $\mathrm{O}$ que mais uma vez não aparece é o aspecto político que dá energia ao processo, e que poderia ser adquirido através de educação continuada.
Se o poder decisório assumir que é necessário rever as concepções de saúde, educação e as práticas educativas vigentes, será necessário que seja oferecido, aos médicos-chefe, além da possibilidade de fazer Curso de Chefia, a oportunidade de atualização e/ou reciclagem sobre o tema saúde e suas formas de abordagem.

É necessário, também que seja estimulado o estabelecimento de um "espaço" de discussão nos PAMs. Considerando que o preparo do pessoal em filosofia, métodos e técnicas educativas inovadas precisam ser combinados e planejados em conjunto, a existência de um espaço de reuniōes torna-se de importância fundamental uma vez que o existente é bastante precário.

Embora as açðes educativas tenham sido lembradas por poucos, como tema de reuniōes, pode-se dizer que em alguns serviços locais já existem experiências de utilização deste espaço para mudança de direcionamento e das práticas médicas e que estas podem ser recuperadas e transmitidas às outras unidades se isto for considerado de importância.

Conforme foi apresentado, grande parte dos problemas mencionados tem a ver com a falta de recursos que deveriam ser providos pela Administração Regional ou Central. Da forma como as situações problemas foram descritas, transparece que as chefias dos PAMs têm possibilidades limitadas de solucionar estas dificuldades identificadas.

Por outro lado, a falta de participação da Administração Central na resolução dos problemas permite inferir que a importância atribuída a ações educativas pela mesma tem sido muito mais em nível de discurso do que de implementação. Com essa omissão do nivel regional e/ou central os médicos-chefe têm ficado, como único responsável pela operacionalização das propostas, respaldadas na boa vontade, esforço, criatividade e competência circunstancial dos servidores que ali atuam. As conseqüĉncias dessa realidade são a descontinuidade, a improvisação, o eterno recomeçar, a não avaliação do impacto dessas ações, entre outras.

Se realmente há uma proposta de implantação de um novo sistema com um novo ideário é necessário verificar, sobre quais concepções ele tentará se sobrcpor e recomeçar a mudança pelo preparo de recursos humanos pela mudança de visão e mentalidade, sem se ater somente a programas de racionalização e organização de serviços, tarefase funçōes.

PEREIRA, I.M.T.B. et al. [Perceptions of head doctors regarding the educational activities undertaken in Municipal Health Services]. Rev. Saúde públ., S. Paulo, 25: 306-14, 1991. The results of a research project carried out along with head-physicians of the Municipal Health Services (PAMs) of the city of S. Paulo in order to survey their knowledge, expectations and willingness 
to participate in and incentivate educational programs in the various PAMs, are reported on. An open-ended questionnaire was answered by $88.6 \%$ of the head-physicians. Results showed that the concept of health of the majority of the PAMs' head-physicians $(66.3 \%$ ) was coincidental with that adopted by the WHO. Only $2.9 \%$ considered that health is related to quality of life. Health education was seen as the provision of information by $70.0 \%$; only $6.7 \%$ recognized their responsibility for the process of social and health change. According to $68.2 \%$ of them, health actions were acknowledged to be useful tools for making the users aware of the importance of having the diseases treated. Health actions, their planing, implementation and evaluation were considered to be the responsibility of all who work at the PAMs, but mainly of nurses, social workers and the health educator. Some difficulties in implementing educational activities were indicated; among them being lack of sufficient material and adequate space for their implementation, lack of professional Public Health Educators and, mainly, a lack of motivation on the part of both staff and population. The majority of the head-physicians recognized that educational activities are important, that they are carried out at least by part of their staffs, although frequently hampered by technical and operational difficulties.

Keywords: Physicians. Knowledge, attitudes, practice. Health education.

\section{Referênclas Bibliográficas}

1. ALVARADO, C.A. Concepto de salud publica. In: Sonis, A., ed. Medicina sanitária y administración de salud. Buenos Aires, Ed. Ateneo, 1971. v. 1, p. 1-20.

2. BARDAN, L. Análise de conteúdo. Lisboa, Ed. 70, 1988.

3. BRASIL. Constituição, 1988. Constituição: República Federativa do Brasil, 1988. Brasília, Ministério da Educação 1988. p. 89-90: $\mathrm{Da}$ ordem social. Art. 201: Da previdência social.

4. BURALII, K.O. \& PEREZ, T. O processo saúde-dœença: um tema em questão. São Paulo, 1988. [Documento elaborado para aula do Curso de Especialização em Saúde Matemo-Infantil. Dept ${ }^{8}$ de Saúde MaternoInfantil/FSP/USP - mimeografado].

5. CLEARY, H.P. Health education: the role and function of the specialist and generalist. Rev. Saúde públ., S. Paulo, 22:64-72, 1988.

6. CONFERENCIA NACIONAL DE SAUUDE, 8", Brasilia, 1986. Anais. Brasilia, Centro de Documentação do Ministério da Saúde, 1987.

7. DECRETO n.8 94.657, de 20 de julho de 1987: dispóe sobre a criação de Sistemas Unificados e Descentralizados de Saúde nos Estados (SUDS) e dá outras providências. In: Secretaria de Estado da Saúde. Uma revoluçâo na área da Saúde. São Paulo, 1988. p. 99.

8. ENCONTRO DE EXPERIÊNCIAS DE EDUCAÇÃO E SAUUDE, Brasília, 1981. Anais. Brasília, Divisão Nacional de Educação em Saúde, 1981.

9. MELO, J.A.C. Educação em saúde. In: Fischmann, R. Escola brasileira: temas e estudos. São Paulo, Atlas, 1987. p. 109-114.

10. SALINAS, C.Q. \& VILLAVERDE, J.A. Función metodológica del concepto de salud en la evaluacion de la meta de salud para todos en el año 2000. Educ. med. Salud, 19: 302-11, 1985.

11. SECRETARIA DE ESTADO DA SAÚDE. Educação em saúde nas programações em saúde. São Paulo, 1987. [Apostila para Treinamento sobre Aspectos Educativos de Vigilância Epidemiológica].

*12. VASCONCELOS, L.P. de et al. Educação em saúde e a reforma sanitária: subsídios para discussão. [Apresentado no XV Encontro de Educadores de Saúde Pública; e I Encontro Estadual de Educação em Saúde, São Paulo, 1987.]

13. WERTHEREL, M \& POTTER, J. Discourse analysis and the identification of interpretative repertories. In: Antaki, C., ed. Analysing every-day explanation. London, Sage, 1988. p. 168-83.

14. WINDSOR, R.A. et al Evaluation of health promotion and education programs. Palo Alto, Mayfield, 1984

Recebido para publicação em 31/01/1991 Aprovado para publicação em 07/06/1991

Cópia disponível com o primeiro autor do presente artigo. 